\title{
Cellulase deactivation based kinetic modeling of enzymatic hydrolysis of steam-exploded wheat straw
}

\author{
Yu Zhang a,b, Jing-Liang Xu ${ }^{\text {a }}$, Hui-Juan $\mathrm{Xu}^{\mathrm{a}}$, Zhen-Hong Yuan ${ }^{\mathrm{a}, *}$, Ying Guo ${ }^{\mathrm{a}, \mathrm{b}}$ \\ ${ }^{a}$ Key Laboratory of Renewable Energy and Gas Hydrate, Guangzhou Institute of Energy Conversion, Chinese Academy of Sciences, Guangzhou 510640, PR China \\ ${ }^{\mathrm{b}}$ Graduate University of Chinese Academy of Sciences, Beijing 100049, PR China
}

\section{A R T I C L E I N F O}

\section{Article history:}

Received 17 March 2010

Received in revised form 1 June 2010

Accepted 2 June 2010

Available online 1 July 2010

\section{Keywords:}

Cellulase kinetics

Enzyme deactivation

Mathematical model

Enzymatic hydrolysis of cellulose

Simulation and prediction

\begin{abstract}
A B S T R A C T
Applying mass action law and quasi-steady-state theory, two cellulase kinetic models namely Eqs. (5) and (8) were developed on the basis of the first and second order reactions of enzyme deactivation, respectively. The two models are compared according to analysis of experimental data from enzymatic hydrolysis steam-exploded wheat straw. Both simulation and prediction results show Eq. (8) has much higher accuracy than Eq. (5). Analysis of initial hydrolysis rate is also in accordance with Eq. (8) and against Eq. (5). Fitted values of $k_{2}$ (the rate constant of product formation), $k_{\mathrm{de} 2}$ (the rate constant of enzyme deactivation) and $K_{\mathrm{e}}$ (the equilibrium constant) determined from Eq. (8) are $0.4732 \mathrm{~h}^{-1}$, $0.4011 \mathrm{~L} /(\mathrm{h} \mathrm{g})$, and $16.8597 \mathrm{~g} / \mathrm{L}$, respectively. The higher the enzyme concentration is, the larger the deactivation rate.
\end{abstract}

(c) 2010 Elsevier Ltd. All rights reserved.

\section{Introduction}

Enzymatic hydrolysis of cellulose to produce reducing sugars has long been pursued for its large potential value in many industries such as bioenergy, food, textile, detergent, animal feed, pulp and paper (Bhat, 2000; Himmel et al., 1999; Sun and Cheng, 2002). To render the enzymatic process much more economical, maximum utilization of cellulase is indispensable. Advances in this aspect partly depend on the development of cellulase kinetics that may accurately quantify feedstock conversion, hydrolysis rate and causes for the rate slowdown during the enzymatic process (Bansal et al., 2009). Toward this aim, many kinetic models including empirical and mechanistic models have been proposed extensively in the past decades (Bansal et al., 2009; Gan et al., 2003; Peri et al., 2007; Xu and Ding, 2007). Empirical models such as artificial neural network and response surface methodology models could accurately predict the enzymatic reaction, and the reaction conditions could always be optimized using these models (Kim et al., 2008; Mussatto et al., 2008; Park et al., 2002; Peri et al., 2007; Zhang et al., 2009; Zhou et al., 2009). However, such models could not provide any insight into the mechanistic details of the process and be applied outside the conditions under which they are developed (Bansal et al., 2009). In contrast, mechanistic models based on certain principles, theories and assumptions, could overcome the drawbacks. These models always contain many differential equations and their parameters are often determined difficultly, which

\footnotetext{
* Corresponding author. Tel.: +86 20 87057735; fax: +86 2087057737 .

E-mail addresses: yuanzh@ms.giec.ac.cn, zhangyu@ms.giec.ac.cn (Z.-H. Yuan).
}

makes the development of them was not a simple thing (Liao et al., 2008; Peri et al., 2007; Zheng et al., 2009). Besides, most of them do not provide guidance on the adjustments of enzyme dosage and hydrolytic time (Shen and Agblevor, 2008a,b). The two factors are critical for economy of cellulase utilization in its related industries (Peri et al., 2007).

It has been generally accepted that cellulase deactivation during the enzymatic hydrolytic process results in some hydrolytic rate slowdown (Gan et al., 2003; Ganesh et al., 2000; Ghadge et al., 2005). Cellulase could be deactivated by many factors including shear force, temperature, ion strength, product inhibition, and ineffective adsorption of cellulase (Demerdash and Attia, 1992; Gan et al., 2003; Gunjikar et al., 2001; Kaya et al., 1996; Kumakura, 1996; Peri et al., 2007; Turner et al., 2003). Many models have been proposed without considering cellulase deactivation (Shen and Agblevor, 2008a).

In this respect, we deduced a simple mathematical equation that directly described the relationship between product concentration and two reaction conditions (initial enzyme concentration and hydrolytic time). Two deactivation models (the first and second order models) were involved in developing the mathematical model.

\section{Methods}

\subsection{Materials}

Crude cellulase powder was provided by Shanghai Bio Life Science \& Technology Co., Ltd. of China. The enzyme activity 
was $74.07 \mathrm{FPU} / \mathrm{g}$, as the measurement described by the description of the Commission on Biotechnology of International Union of Pure and Applied Chemistry (IUPAC) (Ghose, 1987). For the assay procedures described here, $2.0 \mathrm{mg}$ of reducing sugars (glucose equivalents) were produced from a piece of whatman grade No. 1 filter paper $(1 \times 6 \mathrm{~cm}$, about $50 \mathrm{mg})$ at some diluted enzyme solution.

Wheat straw was obtained from a farm in a local harvest. Water immersion made its water content is $50 \%(\mathrm{w} / \mathrm{v})$. It was pretreated by steam explosion for $5 \mathrm{~min}$ at $200{ }^{\circ} \mathrm{C}$ and $1.5 \mathrm{MPa}$. The solid residues was washed three times by distilled water and dried at room temperature. After passed through a 20 meshes sieve, it was used as enzymatic substrate. According to the method of Van Soest (Goering and Van Soest, 1970), the contents of cellulose, hemicellulose and lignin in the pretreated straw were measured as $51.25 \pm 2.23 \%, 17.80 \pm 1.77 \%$ and $25.39 \pm 1.18 \%$, respectively.

\subsection{Enzymatic hydrolysis}

The pretreated straw was hydrolyzed for $12 \mathrm{~h}$ at temperature $50{ }^{\circ} \mathrm{C}$ and $\mathrm{pH} 5.0(0.2 \mathrm{M}$ acetate buffer $)$ and $\mathrm{S} / \mathrm{L}$ ratio of $5 \%(\mathrm{w} / \mathrm{v})$ in a shaking bath $(120 \mathrm{rpm})$. Initial enzyme concentrations of $1.33,2.00,3.33,5.33,8.00,11.33,15.33,20.00$, and $25.33 \mathrm{~g} / \mathrm{L}$ were tested for different times. At each desired time, a sample solution was taken out, and centrifuged at $4000 \mathrm{rpm}$ and $4{ }^{\circ} \mathrm{C}$ for $5 \mathrm{~min}$. The obtained supernatant was kept at $80^{\circ} \mathrm{C}$ for $10 \mathrm{~min}$ and then used for glucose assay.

\subsection{Glucose analysis}

Glucose was determined by the HPLC Waters 2695 system consisting of Waters 600E system controller, Waters 717 automatic sampler, Waters 2414 differential refractometer and Shodex sugar SP-0810 column. The mobile phase was distilled water at a flow rate of $0.6 \mathrm{ml} / \mathrm{min}$. The column temperature was $80^{\circ} \mathrm{C}$. The injected sample volume was $10 \mu \mathrm{l}$. Standard samples and hydrolyzed samples were filtrated by $0.45 \mu \mathrm{m}$ filter before analysis.

\section{Model development}

Cellulase consists of three components is assumed to form a single combined effect on the hydrolysis of insoluble substrate (Carrillo et al., 2005; Movagarnejad et al., 2000; Peri et al., 2007; Shen and Agblevor, 2008a; Shen and Agblevor, 2008b; Xu and Ding, 2007), and the surface structure of insoluble substrate is considered homogeneous (Shen and Agblevor, 2008a,b). The enzymatic hydrolysis reaction can be described as that cellulase $(E)(\mathrm{g} / \mathrm{L})$ is adsorbed on the active sites of the insoluble substrate $(S)(\mathrm{g} / \mathrm{L})$ to form complexes $(E S)(\mathrm{g} / \mathrm{L})$, which continue to produce glucose $(P)$ $(\mathrm{g} / \mathrm{L})$ and release enzyme $(E)$. It is shown as the following equation:

$E+S \underset{k_{-1}}{\stackrel{k_{1}}{\rightleftarrows}} E S \stackrel{k_{2}}{\longrightarrow} E+P$

where $k_{1}(\mathrm{~L} /(\mathrm{h} \mathrm{g})), k_{-1}\left(\mathrm{~h}^{-1}\right)$ and $k_{2}\left(\mathrm{~h}^{-1}\right)$ are the rate constants of enzyme adsorption, enzyme desorption and production formation, respectively.

Applying mass action law and quasi-steady-state theory, a mathematical equation cab be deduced as follow (Shen and Agblevor, 2008a,b):

$[p]=\left[S_{0}\right]\left[1-\exp \left(-k_{2} \int_{0}^{t} \frac{[E]}{K_{e}+[E] d t}\right)\right]$

$K_{e}=\frac{k_{-1}+k_{2}}{k_{1}}$ where $K_{\mathrm{e}}(\mathrm{g} / \mathrm{L})$ is the equilibrium constant. [ $\left.S_{0}\right],[P]$ and $[E]$ represent concentrations of initial substrate, product and enzyme. Eq. (2) expresses the relationship between product (glucose) concentration and hydrolytic time, which indicates that product glucose concentration increases with the time, and the maximum product concentration is $\left[S_{0}\right]$.

In order to obtain the accurate function between glucose concentration and time from Eq. (2), it is required to know the cellulase activity variation during the enzymatic hydrolysis process (cellulase deactivation raw). In our study, product inhibition is involved in cellulase deactivation and the enzyme deactivation is assumed to a first or second order reaction. When cellulase deactivation is considered as a first order reaction, the deactivation rate can be expressed by:

$\frac{d[E]}{d t}=-k_{d e 1}[E]$

where $k_{d e 1}\left(\mathrm{~h}^{-1}\right)$ is the first order rate constant of cellulase deactivation. Integrating Eq. (3) with the initial condition ( $[E]=\left[E_{0}\right]$ at $\left.t=0\right)$ produces

$[E]=\left[E_{0}\right] \exp \left(-k_{d e 1} t\right)$

where $\left[E_{0}\right]$ is the the initial enzyme concentration. Substituting Eq. $(4)$ in Eq. (2) and integrating with the initial condition $([P]=[0]$ at $t=0)$ produces

$[P]=\left[S_{0}\right] \times\left\{1-\left[1-\frac{1-\exp \left(-k_{d e 1} t\right)}{1+K_{e} /\left[E_{0}\right]}\right]^{k_{2} / k_{d e 1}}\right\}$

When cellulase deactivation is considered as a second order reaction, the deactivation rate can be expressed by the following equation:

$\frac{d[E]}{d t}=-k_{d e 2}\left[E^{2}\right]$

where $k_{\mathrm{de} 2}(\mathrm{~L} /(\mathrm{h} \mathrm{g}))$ is the second order rate constant of cellulase deactivation.Integrating Eq. (6) with the initial condition $\left([E]=\left[E_{0}\right]\right.$ at $\left.t=0\right)$ produces

$[E]=\frac{E_{0}}{1+\left[E_{0}\right] k_{d e 2} t}$

Similarly, substituting Eq. (7) in Eq. (2) and integrating with the initial condition $([P]=[0]$ at $t=0$ ) produces (Shen and Agblevor, 2008b):

$[P]=\left[S_{0}\right] \times\left\{1-\left[1+\frac{K_{e}\left[E_{0}\right]}{K_{e}+\left[E_{0}\right]} k_{d e 2} t\right]^{-\frac{k_{2}}{K_{e} k_{d e 2}}}\right\}$

Eqs. (5) and (8) are two three-parameter models that express specific mathematical functions between the product concentration $[P]$ and hydrolytic time $t$ at different initial enzyme concentrations $\left[E_{0}\right]$. In the two equations, $t$ and $\left[E_{0}\right]$ are independent variables, and $[P]$ is dependent variable. Compared to many other models, benefits of the two models include an effective analytical solution, a good convergence for product formation, simple equation and few parameters (only three) (Shen and Agblevor, 2008b). Using such models, enzyme loading and hydrolytic time can be adjusted to obtain the maximum profit of cellulase utilization in industrial applications.

Under similar assumptions, Shen and Agblevor (2008a,b) also deduced a mathematical equation where product concentration approaches infinity when time approaches infinity. It was not suitable for extrapolating the product concentration beyond some time. In contrast, both Eqs. (5) and (8) are not subjected to the time 
limit. It is desired that they could describe the basic characteristics of enzymatic hydrolysis of cellulose.

\section{Results and discussion}

\subsection{Experimental data of enzymatic hydrolysis}

Table 1 shows the effect of initial enzyme concentration and time on the enzymatic hydrolysis. Increasing enzyme concentration and hydrolytic time could produce higher amount of glucose. When enzyme concentration is over $5.33 \mathrm{~g} / \mathrm{L}$, relative small difference is observed probably due to saturation of the substrate. For each enzyme concentration, the hydrolysis rate gets to the maximum value at the initial stage and gradually becomes lower and lower as time increases. Over $50 \%$ glucose is produced within the first $3 \mathrm{~h}$ for each initial enzyme concentration. The slowdown of hydrolytic rate could be caused by enzyme deactivation (major factor), lignin/hemicelluloses/ash against enzyme adsorption and substrate recalcitrance as others have demonstrated (Bezerra and Dias, 2005; Carrillo et al., 2005; Ganesh et al., 2000; Gupta and Lee, 2009; Kim et al., 2003; Shen and Agblevor, 2008b).

\subsection{Eqs. (5) and (8) based simulation}

The experimental data of Table 1 are fitted into Eqs. (5) and (8) using binary nonlinear regression analysis. Fig. 1 shows the plot of the simulated glucose concentration by Eqs. (5) and (8) against the experimentally determined values. The experimental points are apparently closer to the line simulated by Eqs. (8) than that by Eq. (5). The parameters $k_{2}, K_{e}, k_{d e 1}$, and $k_{d e 2}$ determined from the fitting are shown in Table 2. The difference of each parameter determined by Eqs. (5) and (8) is significant. The correlation coefficients $R^{2}$ also indicate that Eq. (8) has better simulation performance than Eq. (5) (see Table 2).

Unary nonlinear regression to fit Eq. (5) was reported by Shen and Agblevor (2008a,b). They considered the three parameters $\left(k_{2}, K_{e}\right.$ and $k_{d e 2}$ ) were related to initial enzyme concentration, and separately fitted experimental data of each initial enzyme concentration. The determined values of $k_{2}, K_{e}$ and $k_{d e 2}$ from the fitting were different at each initial enzyme concentration, and the difference did not present any direct relationship between each parameter and enzyme concentration. As characteristic constants, $k_{2}, K_{e}$ and $k_{d e 2}$ should be determined by enzyme intrinsic property other than enzyme concentration. So unary regression analysis at each enzyme concentration is incorrect and binary regression analysis may be a preferable choice.

\subsection{Eqs. (5) and (8) based prediction}

In order to examine the predictive performance of the model, two experiments (initial enzyme concentrations of 1.33 and $25.33 \mathrm{~g} / \mathrm{L}$ ) were carried out. Fig. 2 shows the plot of experimental glucose concentration against the predicted values by Eqs. (5) and (8). The predictions based on Eq. (8) are closer to the experimental data than that based on Eq. (5). Eq. (8) has higher prediction accuracy than Eq. (5).

\subsection{Analysis of initial hydrolysis velocity}

Initial hydrolysis velocity $v_{0}(\mathrm{~g} /(\mathrm{L} h))$ is a very important parameter when studying cellulase kinetics. Because $v_{0}$ is indefinable for t 0 (division by zero), many researchers take the product determined after some time (i.e. 15 or $60 \mathrm{~min}$ ) as an estimation (Carrillo et al., 2005; Shen and Agblevor, 2008a). Strictly, it is very inaccurate because the invariance stage of hydrolysis rate is no more than few minutes or seconds, and experimental error also exists unavoidably. In this respect, we define $v_{0}$ according the proposed model. Differentiating Eq. (2), $v_{0}$ can be expressed as:

$v_{0}=\left[\frac{d[P]}{d t}\right]_{t=0}=\frac{k_{2}\left[S_{0}\right]\left[E_{0}\right]}{K_{e}+\left[E_{0}\right]}$

On the other hand, Bailey (1989) proposed a more suitable approach by considering the initial hydrolysis rate $v_{0}$ as a function of initial enzyme concentration compared to Henri-Michaelis-Menten equation where $v_{0}$ was taken as a function of substrate concentration. Accordingly, it was convenient to define the maximal initial hydrolysis velocity $V_{\text {emax }}(\mathrm{g} /(\mathrm{Lh}))$ and corresponding halfsaturation constant $K_{m}(\mathrm{~g} / \mathrm{L})$ as Eq. (10) showed:

$v_{0}=\frac{V_{\mathrm{emax}}\left[E_{0}\right]}{K_{m}+\left[E_{0}\right]}$

Comparing Eq. (9) and (10), it can be easily deduced:

$K_{m}=K_{e}$

$V_{\text {emax }}=k_{2}\left[S_{0}\right]$

Substituting data of Table 1 , the calculated $K_{\mathrm{m}}$ and $V_{\text {emax }}$ values are shown in Table 3. It can be known from experimental data of Table 1 that the initial hydrolysis rate exceeds $3 \mathrm{~g} /(\mathrm{L} \cdot \mathrm{h})$ when initial enzyme concentration is over than $5.33 \mathrm{~g} / \mathrm{L}$. As shown in Table 2, the initial hydrolysis rate calculated from Eq. (5) is less than $3 \mathrm{~g} /(\mathrm{L} \mathrm{h})$, which showed disagreement with Eq. (5). Besides, it could be noticed from Eq. (12) that $V_{\text {emax }}$ is related to $\left[S_{0}\right]$. The higher $\left[S_{0}\right]$ is, the larger $V_{\text {emax }}$ is.

Table 1

Glucose production from enzymatic hydrolysis of steam-exploded wheat straw at different initial cellulase concentrations and times.

\begin{tabular}{|c|c|c|c|c|c|c|c|}
\hline \multirow{2}{*}{$\begin{array}{l}\text { Time } t \\
\text { (h) }\end{array}$} & \multicolumn{7}{|c|}{ Initial cellulase concentration $\left[E_{0}\right](\mathrm{g} / \mathrm{L})$} \\
\hline & 2.00 & 3.33 & 5.33 & 8.00 & 11.33 & 15.33 & 20.00 \\
\hline 0 & 0 & 0 & 0 & 0 & 0 & 0 & 0 \\
\hline 1 & $2.248 \pm 0.102$ & $2.644 \pm 0.092$ & $3.088 \pm 0.116$ & $3.580 \pm 0.123$ & $3.832 \pm 0.118$ & $4.032 \pm 0.129$ & $4.500 \pm 0.137$ \\
\hline 2 & $3.108 \pm 0.126$ & $4.208 \pm 0.124$ & $5.548 \pm 0.214$ & $6.064 \pm 0.256$ & $6.528 \pm 0.248$ & $6.904 \pm 0.219$ & $6.932 \pm 0.247$ \\
\hline 3 & $3.812 \pm 0.144$ & $4.856 \pm 0.218$ & $6.252 \pm 0.310$ & $6.792 \pm 0.316$ & $7.296 \pm 0.333$ & $7.800 \pm 0.319$ & $8.048 \pm 0.377$ \\
\hline 4 & $4.420 \pm 0.199$ & $5.544 \pm 0.222$ & $6.952 \pm 0.366$ & $7.560 \pm 0.322$ & $8.024 \pm 0.315$ & $8.480 \pm 0.366$ & $8.792 \pm 0.189$ \\
\hline 5 & $4.868 \pm 0.215$ & $5.992 \pm 0.228$ & $7.396 \pm 0.319$ & $7.976 \pm 0.388$ & $8.500 \pm 0.372$ & $9.048 \pm 0.411$ & $9.240 \pm 0.459$ \\
\hline 6 & $5.228 \pm 0.229$ & $6.436 \pm 0.315$ & $7.948 \pm 0.377$ & $8.596 \pm 0.411$ & $9.124 \pm 0.444$ & $9.492 \pm 0.455$ & $9.776 \pm 0.442$ \\
\hline 7 & $5.584 \pm 0.267$ & $7.072 \pm 0.333$ & $8.432 \pm 0.412$ & $8.992 \pm 0.428$ & $9.520 \pm 0.477$ & $9.924 \pm 0.428$ & $10.192 \pm 0.455$ \\
\hline 8 & $5.828 \pm 0.227$ & $7.496 \pm 0.338$ & $8.796 \pm 0.441$ & $9.328 \pm 0.445$ & $9.864 \pm 0.452$ & $10.368 \pm 0.511$ & $10.556 \pm 0.501$ \\
\hline 9 & $6.164 \pm 0.288$ & $7.749 \pm 0.299$ & $9.065 \pm 0.446$ & $9.625 \pm 0.442$ & $10.040 \pm 0.389$ & $10.484 \pm 0.256$ & $10.884 \pm 0.389$ \\
\hline 10 & $6.425 \pm 0.269$ & $7.901 \pm 0.389$ & $9.298 \pm 0.455$ & $9.892 \pm 0.459$ & $10.356 \pm 0.449$ & $10.766 \pm 0.481$ & $11.189 \pm 0.555$ \\
\hline 11 & $6.702 \pm 0.322$ & $8.252 \pm 0.221$ & $9.436 \pm 0.377$ & $10.084 \pm 0.504$ & $10.524 \pm 0.411$ & $10.996 \pm 0.388$ & $11.356 \pm 0.565$ \\
\hline 12 & $6.919 \pm 0.322$ & $8.401 \pm 0.416$ & $9.665 \pm 0.356$ & $10.291 \pm 0.516$ & $10.702 \pm 0.489$ & $11.201 \pm 0.466$ & $11.551 \pm 0.378$ \\
\hline
\end{tabular}



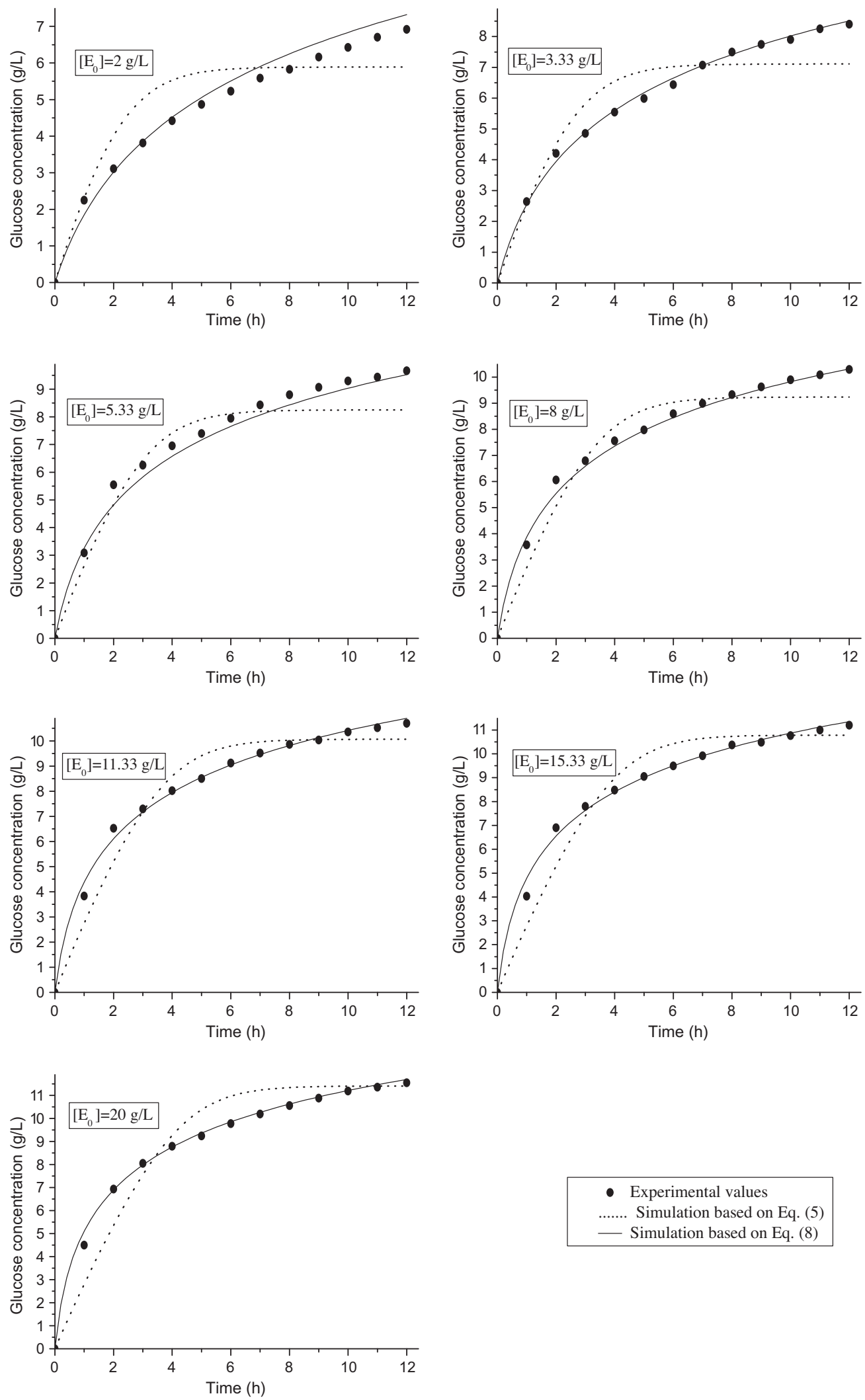

Simulation based on Eq. (5)

- Simulation based on Eq. (8)

Fig. 1. Glucose concentration values simulated by Eqs. (5) and (8) versus experimental values.

\subsection{Analysis of cellulase deactivation}

All the results about simulation, prediction and initial hydrolysis rate indicate that Eq. (8) is much more suitable to study cellulase kinetics as a mechanistic model compared to
Eq. (5). Therefore, we use the parametric values from Eq. (8) to study cellulase deactivation process. According Eq. (7) and parameters of Table 1, the relationship between the retained cellulase activity and time can be expressed as the following equation: 


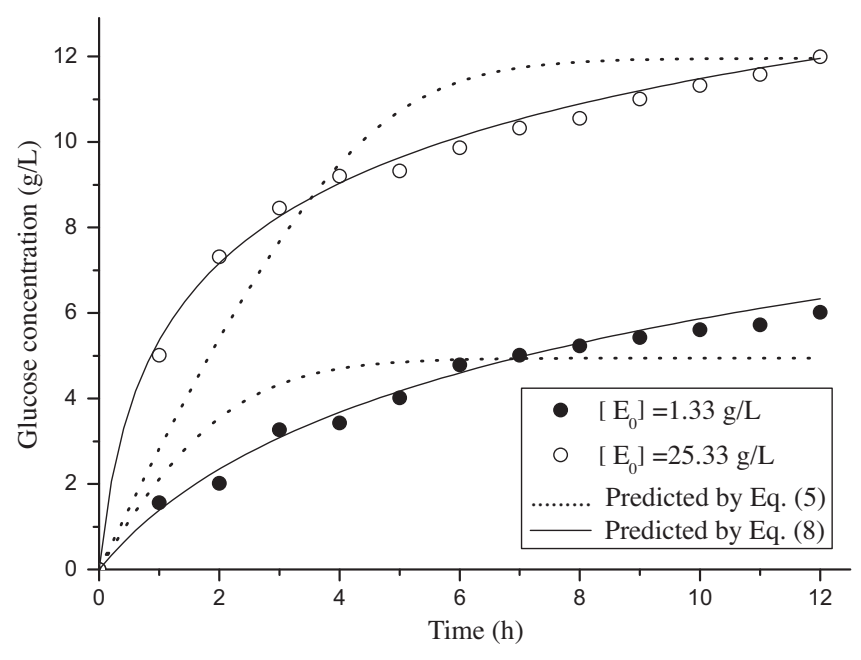

Fig. 2. Glucose concentration values predicted by Eqs. (5) and (8) versus experimental values.

Table 2

Model parameters determined from binary regression analysis of experimental data using Eqs. (5) and (8).

\begin{tabular}{llll}
\hline Parameters & Symbol & Eq. (5) & Eq. (8) \\
\hline Rate constant of product formation & $k_{2}\left(\mathrm{~h}^{-1}\right)$ & 0.0592 & 0.4732 \\
Equilibrium constant & $K_{e}(\mathrm{~g} / \mathrm{L})$ & 0.2983 & 16.8597 \\
Rate constant of enzyme deactivation & $k_{d e 1}\left(\mathrm{~h}^{-1}\right)$ & 0.9644 & -- \\
& $k_{d e 2}(\mathrm{~L} /(\mathrm{h} \mathrm{g}))$ & -- & 0.4011 \\
Correlation coefficient & $R^{2}$ & 0.9455 & 0.9938 \\
\hline
\end{tabular}

Table 3

$K_{m}$ and $\mathrm{V}_{\mathrm{emax}}$ determined from Eq. (9) based on parameters values of Table 1. $V_{\mathrm{emax}}$ is directly proportionate to $\left[S_{0}\right]$.

\begin{tabular}{llll}
\hline Parameters & Symbol & Eq. (5) & Eq. (8) \\
\hline Half-saturation constant & $K_{m}(\mathrm{~g} / \mathrm{L})$ & 0.2983 & 16.8597 \\
Maximal initial hydrolysis velocity & $\mathrm{V}_{\operatorname{emax}}(\mathrm{g} /(\mathrm{L} \mathrm{h}))$ & 2.9595 & 23.6589 \\
\hline
\end{tabular}

$\frac{[E]}{\left[E_{0}\right]}=\frac{1}{\left[E_{0}\right] k_{\text {de2 }} t+1}=\frac{1}{0.4011\left[E_{0}\right] t+1}$

Eq. (13) points out that the retained activity is related to not only time but also initial enzyme concentration. According to Eq. (13), variation curves of cellulase activity during hydrolysis time are presented in Fig. 3. Cellulase loses its activity very quickly, where more than $30 \%$ activity is lost within $1 \mathrm{~h}$. Even no more than $10 \%$ activity is retained after an hour when initial enzyme concentration is $25.33 \mathrm{~g} / \mathrm{L}$. After $12 \mathrm{~h}$, there is less than $20 \%$ retained activity. The higher the enzyme concentration is, the more the loss of cellulase activity is. Opposite results were reported by others who study cellulase deactivation, where cellulase was not involved in hydrolytic process (Ganesh et al., 2000; Kaya et al., 1996; Kim et al., 1982). They thought the higher the enzyme concentration was, the smaller the ratio of enzyme in the high shear and bulk regions was. So the effect of shear force on the rate of enzyme deactivation could be expected to decrease as the enzyme concentration increased (Kaya et al., 1996). The distinction between hydrolytic and non-hydrolytic process is owing to different predominant causes for enzyme deactivation. During non-hydrolytic process, enzyme deactivation is mainly caused by shear force, $\mathrm{pH}$, temperature and ionic strength. Besides these factors, cellulase deactivation in hydrolytic process could still be caused by product inhibition and ineffective adsorp-

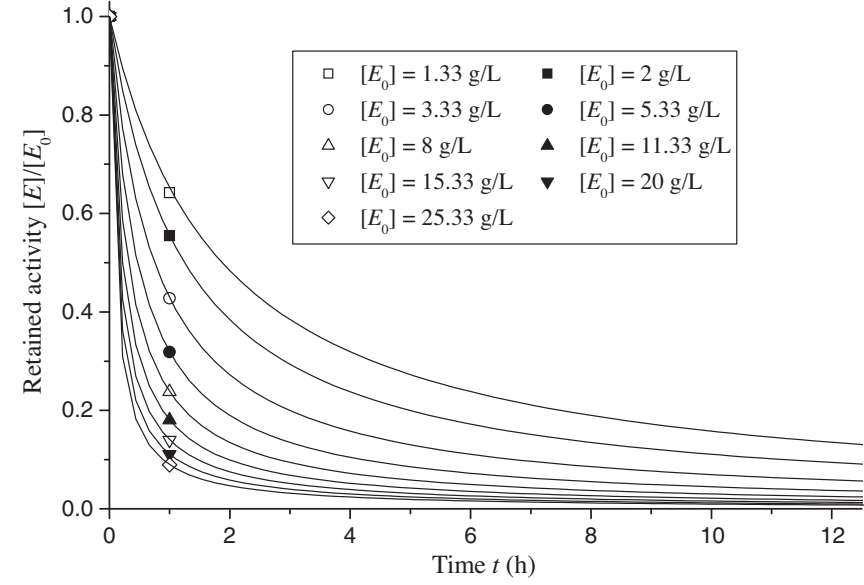

Fig. 3. Effect of initial enzyme concentration on retained activity of cellulase at different times.

tion between enzyme and substrate. These factors are always predominant when cellulase is involved in hydrolytic process. The higher the enzyme concentration is, the more the produced glucose and the unadsorbed cellulase.

\section{Conclusions}

The model based on the second order reaction of enzyme deactivation is preferable during the analysis of simulation, prediction and initial hydrolysis rate of enzymatic hydrolysis steam-exploded wheat straw, compared to that based on the first order reaction. The preferable model is a simple three-parameter mathematical function that directly expresses the relationship between glucose concentration and two hydrolytic conditions (time and initial enzyme concentration). The development of the model could provide some guidance on the adjustments of enzyme dosage and hydrolytic time, which help to maximize cellulase using and evaluate process economy in its related industrial applications.

\section{Acknowledgements}

This work was funded by the Knowledge Innovation Program of the Chinese Academy of Sciences (KSCX-YW-11-A3, KGCX2-YW335 and KSCX2-YW-G-075-9) and the National High Technology Research and Development Program of China (863 program, 2007AA05Z406 and 2009AA05Z436).

\section{References}

Bailey, C., 1989. Enzyme kinetics of cellulose hydrolysis. Biochem. J. 262, 1001. Bansal, P., Hall, M., Realff, M.J., Lee, J.H., Bommarius, A.S., 2009. Modeling cellulase kinetics on lignocellulosic substrates. Biotechnol. Adv. 27, 833-848.

Bezerra, R.M.F., Dias, A.A., 2005. Enzymatic kinetic of cellulose hydrolysis Inhibition by ethanol and cellobiose. Appl. Biochem. Biotechnol. 126, 49-59.

Bhat, M.K., 2000. Cellulases and related enzymes in biotechnology. Biotechnol. Adv. $18,355-383$.

Carrillo, F., Lis, M.J., Colom, X., Lopez-Mesas, M., Valldeperas, J., 2005. Effect of alkali pretreatment on cellulase hydrolysis of wheat straw: Kinetic study. Process Biochem. 40, 3360-3364.

Demerdash, M., Attia, R.M., 1992. Thermal Deactivation Kinetics of Cm-Cellulase from a local isolate of aspergillus-niger (Rd-2231). Zbl. Mikrobiol. 147, 477482.

Gan, Q., Allen, S.J., Taylor, G., 2003. Kinetic dynamics in heterogeneous enzymatic hydrolysis of cellulose: an overview, an experimental study and mathematical modelling. Process Biochem. 38, 1003-1018.

Ganesh, K., Joshi, J.B., Sawant, S.B., 2000. Cellulase deactivation in a stirred reactor. Biochem. Eng. J. 4, 137-141. 
Ghadge, R.S., Patwardhan, A.W., Sawant, S.B., Joshi, J.B., 2005. Effect of flow pattern on cellulase deactivation in stirred tank bioreactors. Chem. Eng. Sci. 60, 10671083.

Ghose, T.K., 1987. Measurements of cellulase activities. Pure Appl. Chem. 2, 257268.

Goering, H.K., Van Soest, P.J., 1970. Forage Fiber Analyses (Apparatus, Reagents, Procedures, and Some Applications). U.S. Agricultural Research Service, Washington.

Gunjikar, T.P., Sawant, S.B., Joshi, J.B., 2001. Shear deactivation of cellulase, exoglucanase, endoglucanase, and $\beta$-glucosidase in a mechanically agitated reactor. Biotechnol. Prog. 17, 1166-1168.

Gupta, R., Lee, Y.Y., 2009. Mechanism of cellulase reaction on pure cellulosic substrates. Biotechnol. Bioeng. 102, 1570-1581.

Himmel, M.E., Ruth, M.F., Wyman, C.E., 1999. Cellulase for commodity products from cellulosic biomass. Curr. Opin. Biotechnol. 10, 358-364.

Kaya, F., Heitmann, J.A., Joyce, T.W., 1996. Deactivation of cellulase and hemicellulase in high shear fields. Cell. Chem. Technol. 30, 49-56.

Kim, J.K., Oh, B.R., Shin, H.J., Eom, C.Y., Kim, S.W., 2008. Statistical optimization of enzymatic saccharification and ethanol fermentation using food waste. Process Biochem. 43, 1308-1312.

Kim, M.H., Lee, S.B., Ryu, D.D.Y., Reese, E.T., 1982. Surface deactivation of cellulase and Its prevention. Enzyme Microb. Technol. 4, 99-103.

Kim, T.H., Kim, J.S., Sunwoo, C., Lee, Y.Y., 2003. Pretreatment of corn stover by aqueous ammonia. Bioresour. Technol. 90, 39-47.

Kumakura, M., 1996. Effect of calcium ions on the irradiation induced inactivation of cellulase. Isot. Environ. Healt. S. 32, 411-419.

Liao, W., Liu, Y., Wen, Z.Y., Frear, C., Chen, S.L., 2008. Kinetic modeling of enzymatic hydrolysis of cellulose in differently pretreated fibers from dairy manure. Biotechnol. Bioeng. 101, 441-451.

Movagarnejad, K., Sohrabi, M., Kaghazchi, T., Vahabzadeh, F., 2000. A model for the rate of enzymatic hydrolysis of cellulose in heterogeneous solid-liquid systems. Biochem. Eng. J. 4, 197-206.
Mussatto, S.I., Dragone, G., Fernandes, M., Milagres, A.M.F., Roberto, I.C., 2008. The effect of agitation speed, enzyme loading and substrate concentration on enzymatic hydrolysis of cellulose from brewer's spent grain. Cellulose 15, 711721.

Park, E., Ikeda, Y., Okuda, N., 2002. Empirical evaluation of cellulase on enzymatic hydrolysis of waste office paper. Biotechnol. Bioprocess. Eng. 7, 268-274.

Peri, S., Karra, S., Lee, Y.Y., Karim, M.N., 2007. Modeling intrinsic kinetics of enzymatic cellulose hydrolysis. Biotechnol. Prog. 23, 626-637.

Shen, J., Agblevor, F.A., 2008a. Kinetics of enzymatic hydrolysis of steam-exploded cotton gin waste. Chem. Eng. Commun. 195, 1107-1121.

Shen, J., Agblevor, F.A., 2008b. Optimization of enzyme loading and hydrolytic time in the hydrolysis of mixtures of cotton gin waste and recycled paper sludge for the maximum profit rate. Biochem. Eng. J. 41, 241-250.

Sun, Y., Cheng, J., 2002. Hydrolysis of lignocellulosic materials for ethano production: a review. Bioresour. Technol. 83, 1-11.

Turner, M.B., Spear, S.K., Huddleston, J.G., Holbrey, J.D., Rogers, R.D., 2003. Ionic liquid salt-induced inactivation and unfolding of cellulase from Trichoderma reesei. Green Chemistry 5, 443-447.

Xu, F., Ding, H.S., 2007. A new kinetic model for heterogeneous (or spatially confined) enzymatic catalysis: Contributions from the fractal and jamming (overcrowding) effects. Appl. Catal. A: Gen. 317, 70-81.

Zhang, Y., Xu, J.L., Yuan, Z.H., Zhuang, X.S., Lu, P.M., 2009. Kinetic model study on enzymatic hydrolysis of cellulose using artificial neural networks. Chin. J. Catal. 30, 355-358.

Zheng, Y., Pan, Z.L., Zhang, R.H., Jenkins, B.M., 2009. Kinetic Modeling for Enzymatic Hydrolysis of Pretreated Creeping Wild Ryegrass. Biotechnol. Bioeng. 102 1558-1569.

Zhou, J., Wang, Y.H., Chu, J., Luo, L.Z., Zhuang, Y.P., Zhang, S.L., 2009. Optimization of cellulase mixture for efficient hydrolysis of steam-exploded corn stover by statistically designed experiments. Bioresour. Technol. 100, 819-825. 